\title{
Text structure instruction: the research is moving forward
}

\author{
Joanna P. Williams ${ }^{1}$
}

Published online: 22 September 2018

(c) Springer Nature B.V. 2018

No one disputes the importance of reading comprehension. It is an absolute requisite for success in school and in life. Thus, it is strange that instruction in comprehension has only recently become a high priority within the reading curriculum. Throughout most of American history, reading instruction has been focused on word recognition, either through some type of phonics training, more or less explicit, or else through an inductive, indirect approach. Attention to comprehension has been minimal, provided mainly via vocabulary instruction. Years ago, grammar instruction was also common, often accomplished through sentence-diagramming exercises. This instruction touched on aspects of comprehension as we understand the term today. However, the focus on grammar died out.

It was not until Dolores Durkin's influential paper appeared, in which she described the dearth of genuine reading instruction in our schools (Durkin, 1978-1979) that we acknowledged that children were being grossly short-changed. Even though most children were learning to "break the code" and could read at least somewhat fluently, a substantial proportion of them did not understand what they read. Now, a few decades later, the amount of research on comprehension has skyrocketed, and we have new models of reading comprehension that have heavily influenced educators. The prominence of comprehension instruction in today's schools reflects our greatly changed view of the importance of this topic.

One thing that we have realized is how important text genre can be. Narrative text, which is generally easier to understand, is usually the genre of choice for beginning instruction. Before they start school, children are exposed to a great deal of narration, through watching TV and movies, and through listening to bedtime stories as well as to adults' conversations (Williams \& Pao, 2011). The content of these narratives is likely to be relatively familiar, which helps understanding. And narrative tends to follow a single structure, in which plot events are sequenced along a causal-temporal line.

But early exposure to expository text is also essential (Duke \& Bennett-Armistead, 2003). Reading expository text increases domain knowledge, which in turn leads to increased vocabulary, fluency, and motivation (Guthrie, Anderson, Alao,

Joanna P. Williams

jpw15@columbia.edu

1 Teachers College, Columbia University, New York, NY, USA 
\& Rinehart, 1999). However, understanding expository text is often a challenge, especially for children with language and other learning difficulties. Children who do not receive sufficient early exposure to, and instruction about, expository text are likely to have more and more difficulty with reading as they proceed through the grades (Kucan \& Beck, 1997). By the time they reach the sixth grade, the majority of children's school reading assignments are expository texts, and these children encounter serious problems in meeting academic demands.

Lack of exposure is only one of the reasons for the relative difficulty of expository text. In addition, exposition often tends to deal with more challenging content; the ideas are less familiar and often more complex than those in narrative text (Kucan \& Beck, 1997). Moreover, expository text is not structured as simply as is narrative text; there are several basic expository structures (Calfee \& Chambliss, 1988; Meyer, 1985).

Unfortunately, some teachers spend very little time in their classrooms on expository text (Williams \& Pao, 2011). And sometimes those who do focus on such text are burdened by textbooks that are badly organized and poorly written. Teachers often respond by reading the texts aloud to their students instead of trying to teach them to read and understand the texts by themselves. Obviously this is not a good solution-it takes away opportunities for students to learn. Moreover, while teachers who read to their class may side-step difficulties due to decoding problems, the students are often still getting their information from disorganized texts.

In the late 1990s, when the National Reading Panel (NRP) was convened to examine the existing research literature and to synthesize our knowledge about beginning instruction, the new thinking about comprehension had only recently been introduced. The NRP Report (2000) on comprehension included a chapter on vocabulary, of course; vocabulary is always a prominent topic in a reading program no matter what the current educational focus. The Report also focused on cognitive strategies, a new approach in which comprehension instruction is conceptualized as the teaching of ways in which a student can consciously and deliberately approach a text in order to uncover its meaning. One such strategy (that had generated a substantial amount of research before the NRP panel reviewed the literature) is to use background knowledge. That is, students who are about to read a text are told to consider what they already know about the topic. Information that they activate from their store of knowledge, when incorporated with the new information presented in the text, will aid in their comprehension. Another commonly taught cognitive strategy is self-monitoring, that is, stopping occasionally while reading, in order to reflect on whether one is fully understanding what one is reading, and, if one is not, to reread the text. The NRP Report was very influential and ensured that the cognitive strategy approach was solidly entrenched as the way to teach reading comprehension.

Text structure was another item in NRP's rather lengthy list of cognitive strategies. Since the Report was published, however, text structure has emerged as a topic in its own right. Arguably, text structure did not belong in the list of cognitive strategies in the first place. The classic notion of cognitive strategy implies either that readers are monitoring their own reading activity to evaluate its effectiveness or that they are performing some additional activity while 
reading, such as trying to remember previously acquired information that might help them understand the text in front of them.

It is true that readers consciously attend to text structure when they decide to read titles and paragraph headings in order to get an overview of a text. In that sense one might consider the use of text structure as a cognitive strategy. However, there are structural cues of all sorts within text, some easy to identify and some rather subtle. Most of the research on text structure deals with normal reading, in which the instruction is geared toward getting the reader to respond to such textual cues without paying undue attention to them. This instruction is straightforward, similar to phonics instruction. We teach beginners lettersound correspondences and a method of combining the sounds represented by the letters into words. But we expect that fluent readers will be able to recognize words automatically without consciously attending to their phonics skills. In the same way that I would not consider that fluent readers typically use their phonics skills as a strategy (though they might do so when reading scientific text or Russian novels), I would not consider that fluent readers typically use their text structure skills as a cognitive strategy. Of course, faced with a stumbling-block in the text, the fluent reader can quite deliberately go back to using text structure skills to work through the difficulty and reach a good level of understanding.

The seminal work on expository text structure was done by Meyer (1975). She posited that readers understand a text more readily if they recognize the specific structure according to which the writer has organized the text. They will then be able to use the writer's structure to create their own mental representation of the text. The five basic structures identified by Meyer are description, sequence, comparison, cause-effect, and problem-solution. These structures are really representations of rhetorical structures. Fundamental concepts such as causality and comparison arise initially through perception and action during the first year of life (Saxe, Tzelnic, \& Carey, 2007). As these primitive understandings mature and language develops, discourse patterns basic to both oral and written language that express these concepts appear (Williams et al., 2016). It is the ability to transfer what is known about these structures in oral language to written language that is the goal of teaching text structure.

Meyer's analysis fits in well with Kintsch's $(1998,2004)$ more comprehensive construction-integration model of reading comprehension. In this model, text information activates readers' background knowledge, and then this activated knowledge is integrated with the information presented in the text. Signals in the text, including order of mention, repetition, clue words, etc., indicate relationships among pieces of information and affect the amount of activation given to certain pieces. In this way, the reader is guided to identify the macrostructure of the text (the important information) and to organize it into a coherent mental representation. When the text is not well structured, readers must expend cognitive resources on creating their own organization, which may or may not be effective in deriving the writer's purpose and argument. 


\section{Close analysis of texts with structure (CATS)}

I was asked to contribute to this special issue by writing an introduction that would include some discussion of my own work on the topic. When I started thinking about using text structure as the focal point of an intervention, it was not the popular topic of research that it has now become. Meyer had made substantial contributions (as she is continuing to do), but not many investigators had yet followed suit. Meyer was working with adults and students at the middle school level (fourth and fifth-graders). I became interested in what one might do in the way of using text structure as the focus of instruction with younger children. I decided to work at the second-grade level, because I wanted to make sure that students had sufficient reading skill to be able to focus on structure.

My program combined explicit instruction in reading comprehension and content-area instruction. I specified as its goals (a) ensuring that children could use their knowledge of basic rhetorical structures in reading as they already could use them in listening, and (b) laying the foundation for further development of their comprehension of these structures in both reading and listening.

I call the intervention Close Analysis of Texts with Structure (CATS). I first described it in a 2004 paper (Williams, Hall, \& Lauer, 2004). The intervention is designed to serve as supplemental instruction for general education classrooms, especially for struggling readers in those classrooms. With adaptations it can be differentiated for use with students who have learning disabilities. The instructional model includes both direct and strategic instruction (Kame'enui \& Carnine, 1998; Pressley, 1998), which when used together, produce the largest effect sizes for at risk learners (Swanson \& Hoskyn, 1998). The instruction is structured, explicit, scaffolded, and intensive. It proceeds systematically from the simple to the complex, and it provides substantial practice at each step. The tasks are meaningful and interesting; they include specially-designed training materials (texts) that provide simple, clear templates that exhibit instructional points (Williams et al., 2014). My graduate students, cohort after cohort, have participated fully in all stages of the development of the intervention and its evaluation.

The core of the instruction consists of the close analysis of short paragraphs of well-structured text that embody each of the five basic text structures. I believe that a deep and extensive study of a series of clear examples of a given structure will help students become familiar with the way in which these basic patterns are manifested in print and will lead to a strengthening of their mental representations of the structures. The instruction guides students through an analysis of well-structured paragraphs, and they become familiar with basic structure patterns. To aid in this analysis, we teach children to use three well-documented strategies in their analysis of text: clue words (e.g., next; unlike; because), targeted questions, and graphic organizers. Goldman and Rakestraw (2000) have presented ample evidence that each of these three strategies is effective in helping readers identify global discourse structure and establish local coherence. The analysis of prototypical texts, accomplished with the help of these three strategies, comprises the core of the CATS program. The lessons also include common 
instructional components: trade book reading by the teacher followed by discussion, vocabulary, and a heavy dose of writing, so that the instructional setting is well within the context of a typical elementary-level lesson in the language arts.

The content of our intervention covers a typical second-grade social studies curriculum. Units focus on five historical communities in the United States: Native Americans, colonists, pioneers, immigrants, and urban residents. Students learn about the homes, schools, jobs, and other features of these communities.

We developed the procedures for the text analysis and the strategies for each individual text structure through an iterative series of develop-tryout-test cycles with small groups of children. We did small-scale randomized clinical trials, each one on a single text structure (Williams et al., 2005, 2007, 2009, 2014). Then we developed our year-long comprehensive intervention (Williams et al., 2016), which included all five text structures.

We evaluated our complete intervention in second-grade classrooms drawn from NYC elementary schools (Williams et al., 2016). Classrooms were randomly assigned to three conditions, all of which received the school's regular reading instruction; the intervention was a twice-a-week supplement. Students in one condition (CATS) received the text structure intervention. In another condition (No Intervention) there was no intervention. The third condition provided a much more stringent control. Classrooms in this group used a version of our intervention that was the same as the CATS intervention in all respects except one. That is, it included the same content and the same materials (books, tasks, tests), and the number of lessons and mean amount of time spent on them did not differ. However, students in this latter condition received no text structure training. We called this the Content condition, because it essentially focused on the social studies content-information about the five U.S. communities.

Students in classrooms that received the CATS intervention scored significantly higher than those in the No Intervention classrooms on the comprehension posttest, as assessed by their written summaries of five novel paragraphs, one of each structure. Specifically, they were better able to report the main idea as well as the important information about the main idea, and better able to identify the particular structure of the paragraphs. These measures, most of which were derived from the paragraph summaries, comprised our basic reading comprehension measures.

The CATS students were also superior on measures of transfer, i.e., on measures based on comprehension tasks other than those that were featured in the instruction. These included a measure based on a sentence completion task involving social studies content and two measures based on written summaries of natural text taken from authentic reading materials (children's trade books), which, as is characteristic of such material, were not well structured. All three transfer measures showed significant differences in favor of the CATS condition. The test items that were based on natural text represented a level of transfer that is difficult to achieve; here, the effect sizes were smaller than the effect sizes on the other measures (though they were still significant). If I were to extend this intervention for use in higher grades, I would include explicit instruction that uses exemplars of the various text structures as they appear in natural prose. Our instructional paragraphs did get progressively longer and more complex as instruction continued, but they did not include text as 
ill-structured as we sometimes see in books and magazines. However, I would still make certain that the students were given initial instruction based on well-structured paragraphs; I believe that this was an important factor in the success of the intervention.

More interesting was the fact that we found that the superiority of the CATS students on these comprehension measures also occurred in comparisons with students in the Content classrooms. In fact, the Content classrooms and the No Intervention classrooms did not differ on any of these measures. This suggests that explicit and systematic instruction about text structure is necessary. We cannot rely simply on providing exposure to structured texts if we want to make an impact on children's understanding.

In contrast, on measures assessing the amount of social studies content that was learned, the CATS classrooms and the Content classrooms did not differ, and students in both of these conditions scored higher than students in the No Intervention classrooms. Thus we can embed text structure training in content-area instruction without sacrificing acquisition of the academic content. This is important; it would be less than optimal if it turned out that we could improve reading comprehension only at the expense of the content-area instruction.

We were fortunate to be able to go through multiple development-try out-test cycles on each individual text structure before producing the final complete intervention (which also involved multiple iterations). As we worked, we made many modifications that improved the instruction in one way or another. Most were small changes, but we also made some changes that were rather important from a design point of view. First, it became clear very early in our pilot work that the instruction typically given to older students in which students used clue words as the initial identifiers of a text's structure (e.g., Wijekumar et al., 2014), was not appropriate for our younger students. Second-graders do not have sufficient reading skill to be able to scan text in order to pick out clue words. So we began each paragraph with a topic (main idea) sentence that indicated its structure type. Later, perhaps in third grade, students would probably have sufficient reading skill to identify clue words easily and would be able to work with paragraphs that do not begin with a main idea sentence.

Second, we did not introduce the five structures in the same order as many other investigators had introduced them. Description, as defined by Meyer and Freedle (1984), is a type of association in which some elements are subordinate to another (the topic). In most of the second grade classrooms we were working in, teachers were already teaching children this type of simple descriptive structure, which they called the information web. A web does not represent structured text at the level of the other four structures. In our intervention, the Description structure is more challenging: it reflects the idea of an information hierarchy. We taught Description as the fourth in the series of five structures.

We also discovered that it would be best to vary the ways in which we mapped the complete structure across the paragraph, and this led to our third modification. We organized the Sequence sentences across the entire paragraph. That is, each sentence in the paragraph represented one step in the sequence. However, in the causation paragraphs, the entire structure appeared in individual sentences, i.e., each 
sentence contained both cause and effect, plus a suitable clue word. Our comparison paragraphs were also structured at an individual-sentence level. In the other two text structures, Description and Problem/Solution, the complete structure was represented in sentence pairs. We found justification for these mappings in several studies that have found that organizing instructional tasks at the sentence level is appropriate for primary-grade children (Berninger, Nagy, \& Beers, 2011; Crosson, Lesaux, \& Martiniello, 2008).

Across the several studies we conducted, our posttests included both oral and written responses on a variety of tasks not used in the intervention. We have found that our text structure instruction helps young students comprehend text and acquire new vocabulary. Instructional effects transfer to novel text about topics both similar to and different from those used in the intervention. We also found that training on one structure (compare-contrast) improves the ability to learn a similar structure (pro-con). And we have found a little evidence that the intervention makes it easier for children to comprehend authentic, ill-structured texts. This of course is the ultimate goal of text structure instruction - that a reader be able to mentally re-organize poorly written text and thereby better comprehend and remember it. Of course, reaching this goal would involve instruction and/or practice over years of schooling - well beyond the scope of our intervention project.

In summary, our work demonstrates the effectiveness of explicit reading comprehension instruction for primary-grade students. It also demonstrates that text structure is a useful focus for training. It should be kept in mind, however, that CATS is a supplemental program, not a full reading comprehension program. The latter would be much more comprehensive. But on the basis of this work as well as that of the other researchers who have contributed to the research base, I am prepared to say that text structure instruction should be included as a prominent part of a complete reading comprehension curriculum.

I have described the work I have done as an example of what might be considered the first generation of text structure research, in which text structure has been shown to be useful knowledge for a young reader to acquire, and also that it can be taught successfully. Systematic reviews of text structure research (e.g., Ray \& Meyer, 2011) have collated the substantial amount of literature relevant to the constructing of an intervention to teach text structure. In addition, two recent meta-analyses of text structure interventions across the grades have been published, and it is clear from these that this type of instruction is feasible to do, that it is effective, and that it can provide a strong foundation for later progress in reading comprehension (Hebert, Bohaty, Nelson, \& Lambert, 2016; Pyle et al., 2017).

\section{The articles in this issue}

Now that we have enough documentation about the importance of text structure instruction and its effectiveness, we are ready to move ahead. The papers that comprise this issue indicate that there is indeed a flourishing second generation of relevant research. The authors have tackled important questions that build on the existing evidence of the importance of text structure instruction. 
I am going to begin my comments on the individual articles with the study by Meyer, Wijekumar, and Lei. Bonnie Meyer is the doyenne of text structure research, the one who introduced the topic (Meyer, 1975) and who conducted the earliest studies that showed the effectiveness of the text structure strategy. Meyer developed an intervention for middle-school students that later she turned into a computer-based program, ITSS, which was first introduced in 2002 (Meyer et al., 2002) and which has been evaluated extensively in many variations. Over the years a great many students ranging from fourth-graders to retirees have profited from this instructional program. A substantial amount of data has been collected-a wonderful resource for further study. The article in this issue reports on a close examination of the effects of signal words, one of the most salient textual cues as to structure. Using data sets from evaluations of the ITSS intervention that yielded data from over 7000 students, the authors analyzed a pretest and posttest of generative signaling that had been administered across studies. Differences as a function of type of signal word, gender, and grade level (grades 4-8) were examined. In addition to providing insights about signal words, this study demonstrates the value of designing intervention evaluations in such a way that they address targeted questions concerning specific aspects of the intervention as well as provide an overall evaluation of the intervention.

Another paper authored by the same research team (Wijekumar, Meyer, Lei, Hernandez, and August) describes SWELL, Spanish instruction on the Web for English Learners. This intervention provides one-on-one instruction. It responds to the challenges that children face when they are learning in a non-dominant language. SWELL contains special adaptations, which include vocabulary instruction, contextual cues, and on-line translations of unfamiliar and difficult words and sentences. The authors report on the evaluation of the intervention, which was conducted in grades 4 and 5 classrooms in high poverty schools. Results were positive: Students who received the intervention showed better performance than students who did not receive it on both researcher-developed measures and a standardized test of reading comprehension. The authors also examined the effect of moderating factors like initial reading level and gender.

The articles in this issue reflect the fact that the field has devoted most of its attention to students in middle school and above. Only a couple of these papers focus on the primary grades. They are most welcome! Al Otaiba, Connor, and Crowe present three brief interventions, each on a single text structure, and they look at kindergarten, first and second grade effects. This work is a pilot study for a larger intervention study now in progress. The authors use what they call a pattern exploration design, carefully thought through to allow evaluation of explicit training on each of the three taught structures along with transfer to each of four structures (the three that were taught plus one other). The authors' choice of instructional routines, e.g., reliance on clue words and graphic organizers, reflects the consensus in the field about how to approach the teaching of text structure. They also included practices less often used in text structure research, such as manipulatives to scaffold retells, which appear to be particularly useful with young students. Preliminary results from their initial work are promising in terms of promoting both acquisition and transfer.

Van den Broek, Kraal, Koornneef, and Saab also study primary-grade children, but their work is of a different nature. They do not conduct an intervention, prepare 
to do one, or examine aspects of a completed intervention. Rather, they ask a more fundamental question about how second-graders process text; the answer to this question should be of help to future interventionists. They ask whether the same intervention is likely to be optimal for all students. An analysis of think-aloud protocols collected during the reading of both narrative and expository texts indicates that children fall into one of two categories. There are those whose mental representation of a text tends to conform to the textual information (paraphrasers), and those whose processing is more elaborative, which leads to a broader, more wide-ranging representation (elaborators). Also, these two types of readers respond in different ways to expository and narrative text. The authors suggest that different types of questioning during instruction might be appropriate for paraphrasers and elaborators. What might these findings mean for the instructional model that is the basis for most current text structure interventions?

A classic question of second-generation research has to do with context. Beerwinkle, Wijekumar, Walpole, and Agius consider the context in which text structure instruction appears, or, as they put it, the ecological component within a componential model of reading. They examine the extent of knowledge that fourth and fifthgrade teachers have about text structure, and they also look at the way children's textbooks cover the topic. In addition, they describe their observation of classrooms as teachers delivered text structure instruction. Their work indicates that there is considerable room for improvement on all counts. Beerwinkle and her colleagues are persuasive on the point that research to improve text structure instruction should continue, but that we need to extend our efforts beyond simply developing excellent instructional materials. We must also ameliorate the context in which the instruction occurs.

How does the ability to deal with text structure, a rather specific and circumscribed aspect of reading comprehension, fit into a comprehensive reading comprehension model? Welie, Schoonen, and Kuiken administered a battery of tests to eighth-graders, including tests of expository text comprehension, sentence reading fluency, linguistic knowledge (general vocabulary and connectives), metacognitive knowledge (knowledge of reading strategies), and text structure inference skill. The participants included both monolingual students, who spoke only Dutch, and bilingual students who spoke a minority language at home. Two important factors emerged from a series of hierarchical regression analyses: knowledge of connectives and metacognitive knowledge. The authors conclude that interventions focused on text structure should include instruction on both of these topics. The authors also examined their data to determine whether there were differences as a function of students' language background or level of reading proficiency.

The article by Ji, Beerwinkle, Wijekumar, Lei, Joshi, and Zhang offers an alternative method of analyzing intervention effects. In Latent Transition Analysis (LTA), students are classified on the basis of their scores on a set of pretest measures, such that the score profiles of the classes are distinct from one another. After the intervention has been completed, the posttest is examined to determine the probability of the students in any given class transitioning to the score profile of another class. In the study reported here, which was based on almost 2000 seventh-graders, an LTA identified four classes of students who exhibited various 
patterns of performance on a pretest of text structure comprehension. Transitional probabilities from pretest to posttest indicated that progress toward proficiency differed among the classes. This new approach to modeling intervention effects allows one to track the stability of each class of students over time. It also provides more specific information that can guide the design of instruction, perhaps leading to a decision to modify an intervention in different ways for different classes of students.

We are all used to reading in reports of intervention evaluations that a useful next step in the research would be to analyze the components of that intervention in order to determine which ones were the effective ones. Answering that question would help us develop not only effective, but efficient interventions. However, we rarely come across an actual study that undertakes such an analysis, probably because it appears to be a rather daunting endeavor. Hebert, Bohaty, Nelson, and Lambert take an unconventional approach to determining how much each individual component of an intervention contributes to its ultimate effectiveness. What they have decided to do is to attempt to answer this question even as they construct their intervention. That is, they are building an intervention one component at a time. In the present study the authors evaluate instruction on the component of identification/discrimination for fourth and fifth-grade struggling readers. They plan to collect data on each of several intervention components. It is interesting to contemplate how the results of this approach might differ from those of the decomposition strategy that is typically considered the way to approach the question.

Incorporating writing tasks as part of reading comprehension instruction is acknowledged to be a powerful instructional strategy. However, there is little research on the use of writing as a means of improving text structure knowledge. Turcotte, Berthiaume and Caron have examined how well French-speaking students in grade 6 of Canadian schools deal with text structure in both reading and writing tasks. The students had no specific training in text structure prior to the study. Path analysis indicated that knowledge of text structure and ability to identify main ideas influenced reading comprehension, which in turn influenced writing proficiency. The attention directed in this study to what students with no formal instruction can and cannot do is unusual. Interventions might sometimes be substantially improved if there were a deeper understanding of students' abilities at the point at which they were introduced to the intervention. (This observation is certainly not limited to interventions that incorporate writing instruction.)

The article by Hebert, Bohaty, Nelson, and Roehling focuses specifically on writing instruction. These authors want to help struggling readers learn to organize text in order to improve their writing. Their idea is to free up students' cognitive resources by including in their instruction only what is essential for teaching planning and organizing-in other words, executive function. In their intervention students do not have to be concerned about what to write about, which is a complicating factor in most writing instruction. The authors provide students with short information "frames", which eliminate the need to generate content; students learn to organize the frames according to the several text structures. Further work on this project will culminate in a longer, more comprehensive writing intervention and perhaps also more theorizing about the nature of executive function. 
Arfe, Mason, and Fajardo discuss another way, in addition to direct instruction, that we might address the comprehension difficulties of struggling readers. Problematic text could be modified to make it more accessible. Arfe et al. present their recent work on text simplification. They show how cognitive models of discourse comprehension can guide us to construct texts that will cue readers to form sound mental representations and accurate understandings. They describe one such system, currently under development, in which texts are rewritten to improve both global and local coherence and to decrease linguistic complexity (both vocabulary and syntax). They discuss the value of having a system that provides texts that are graded in difficulty, both for instruction and for practice.

\section{Summary}

The articles that appear in the present issue address many of the issues raised in the review by Ray and Meyer (2011) and the two meta-analyses (Hebert et al., 2016; Pyle et al., 2017) that I cited earlier. These articles are indeed very heterogeneous-much too varied for me to draw any general conclusions about any specific issue. However, one observation worth making is that it appears that much of the research included in the two meta-analyses was based on English-speaking students and texts written in English. In contrast, the present issue includes participants who speak Dutch, Spanish, and French as well as English. While this hardly qualifies as a representative sample of world languages, it is a start to being able to generalize the results of text structure instruction beyond the English-speaking world.

I will also note that one of the most frequent second-generation research questions has to do with moderating variables. The papers in this collection that look for moderators come up rather surprisingly short of expectation. There are not a lot of data here that suggest, for example, that level of reading proficiency or grade level interacts importantly with text structure instruction. One interesting finding is the distinction between paraphrasers and elaborators that van den Broek and his colleagues have identified. Perhaps it would be worthwhile to study the performance of these two types of reader on texts of the kind that are typically used in a text structure intervention.

All in all, this is a provocative set of studies that expands the horizons of text structure research. It is clear that the field is continuing to move forward and that current and future findings will further inform all those involved in the quest for optimal instruction. I look forward to reading further studies by the researchers who have contributed to this volume as they continue to pursue their particular questions. All of them are on the path to better understanding of what has rightly come to be considered an important part of reading comprehension instruction.

\section{References}

Berninger, V. W., Nagy, W., \& Beers, S. (2011). Child writers' construction and reconstruction of single sentences and construction of multi-sentence tests: Contributions of syntax and transcription to translation. Reading and Writing, 24, 151-182. https://doi.org/10.1007/s11145-010-9262-y. 
Calfee, R., \& Chambliss, M. (1988). Beyond decoding: Pictures of expository prose. Annals of Dyslexia, 38, 243-257. https://doi.org/10.1007/bf02648259.

Crosson, A. C., Lesaux, N. K., \& Martiniello, M. (2008). Factors that influence comprehension of connectives among language minority children from Spanish-speaking backgrounds. Applied Psycholinguistics, 29, 603-625. https://doi.org/10.1017/S0142716408080260.

Duke, N. K., \& Bennett-Armistead, V. S. (2003). Reading and writing informational texts in the primary grades: Research-based practices. New York: Scholastic.

Durkin, D. (1978-1979). What classroom observations reveal about reading comprehension instruction. Reading Research Quarterly, 14, 481-533.

Goldman, S. R., \& Rakestraw, J. A. (2000). Structural aspects of constructing meaning from text. In M. L. Kamil, P. B. Mosenthal, P. D. Pearson, \& R. Barr (Eds.), Handbook of reading research (Vol. 3, pp. 311-335). Mahwah, NJ: Erlbaum.

Guthrie, J. T., Anderson, E., Alao, S., \& Rinehard, J. (1999). Influences of concept-oriented reading instruction on strategy use and conceptual leading from text. Elementary School Journal, 99, 343-366.

Hebert, M., Bohaty, J. J., Nelson, J. R., \& Brown, J. (2016). The effects of text structure instruction on expository reading comprehension: A meta-analysis. Journal of Educational Psychology, 108(5), 609.

Kame'enui, E. J., \& Carnine, D. W. (Eds.). (1998). Effective teaching strategies that accommodate diverse learners. Columbus, $\mathrm{OH}$ : Merrill.

Kintsch, W. (1998). Comprehension: A paradigm for cognition. New York, NY: Cambridge University Press.

Kintsch, W. (2004). The construction-integration model of text comprehension and its implications for instruction. In R. Ruddell \& N. Unrau (Eds.), Theoretical models and processes of reading (5th ed., pp. 1270-1328). Newark, DE: International Reading Association. https://doi. org/10.1598/0872075028.46.

Kucan, L., \& Beck, I. L. (1997). Thinking aloud and reading comprehension research: Inquiry, instruction, and social interaction. Review of Educational Research, 67, 271-299.

Meyer, B. J. (1975). The organization of prose and its effects on memory. Amsterdam: North-Holland Publishing Co.

Meyer, B. J. F. (1985). Prose analysis: Purposes, procedures, and problems. In B. K. Britton \& J. B. Back (Eds.), Understanding expository text (pp. 11-65). Hillsdale, NJ: Erlbaum.

Meyer, B. J. F., \& Freedle, R. O. (1984). Effects of discourse type on recall. American Educational Research Journal, 21, 121-143. https://doi.org/10.3102/0002812021001121.

Meyer, B. J., Middlemiss, W., Theodorou, E., Brezinski, K. L., McDougall, J., \& Bartlett, B. J. (2002). Effects of structure strategy instruction delivered to fifth-grade children using the internet with and without the aid of older adult tutors. Journal of Educational Psychology, 94(3), 486.

National Reading Panel (US), National Institute of Child Health, \& Human Development (US). (2000). Report of the national reading panel: teaching children to read: An evidence-based assessment of the scientific research literature on reading and its implications for reading instruction: Reports of the subgroups. Bethesda: National Institute of Child Health and Human Development, National Institutes of Health.

Pressley, M. (1998). Reading instruction that works: The case for balanced teaching. New York, NY: Guilford Press.

Pyle, N., Vasquez, A. C., Gillam, S. L., Reutzel, D., Olszewski, A., Segura, H., et al. (2017). Effects of expository text structure interventions on comprehension: A meta-analysis. Reading Research Quarterly, 52(4), 469-501.

Ray, M. N., \& Meyer, B. J. F. (2011). Individual differences in children's knowledge of expository text structures: A review of the literature. International Electronic Journal of Elementary Education, 4, 67-82.

Saxe, R., Tzelnic, T., \& Carey, S. (2007). Knowing Who Dunnit: Infants identify the causal agent in an unseen causal interaction. Developmental Psychology, 43, 149-158. https://doi. org/10.1037/0012-1649.43.1.149.

Swanson, H. L., \& Hoskyn, M. (1998). Experimental intervention research on students with learning disabilities: A meta-analysis of treatment outcomes. Review of Educational Research., 68, 277-321. https://doi.org/10.3102/00346543068003277. 
Wijekumar, K., Meyer, B. J. F., Lei, P.-W., Lin, Y. C., Johnson, L. A., Spielvogel, J. A., et al. (2014). Multisite randomized controlled trial examining intelligent tutoring of structure strategy for fifth-grade readers. Journal of Research on Educational Effectiveness., 7, 331-357.

Williams, J. P., Hall, K. M., \& Lauer, K. (2004). Teaching expository text structure to young at-risk learners: Building basics of comprehension instruction. Exceptionality, 12, 129-144. https://doi. org/10.1207/s15327035ex1203_2.

Williams, J. P., Hall, K. M., Lauer, K. D., Stafford, K. B., DeSisto, L. A., \& de Cani, J. S. (2005). Expository text comprehension in the primary grade classroom. Journal of Educational Psychology, 97, 538-550.

Williams, J. P., Kao, J. C., Pao, L. S., Ordynans, J. G., Atkins, J. G., Cheng, R., \& DeBonis, D. (2016). Close analysis of texts with structure (CATS): An intervention to teach reading comprehension to at-risk second graders. Journal of Educational Psychology, 108, 1061-1077.

Williams, J. P., Nubla-Kung, A. M., Pollini, S., Stafford, K. B., Garcia, A., \& Snyder, A. E. (2007). Teaching cause-effect text structure through social studies content to at-risk second graders. Journal of Learning Disabilities, 40, 111-120. https://doi.org/10.1177/00222194070400020201.

Williams, J. P., \& Pao, L. S. (2011). Teaching narrative and expository text structure to improve comprehension. In R. E. O'Conner \& P. F. Vadasy (Eds.), Handbook of reading interventions (pp. 254278). New York: Guilford Press.

Williams, J. P., \& Pao, L. S. (2014). Developing a new intervention to teach text structure at the elementary level. In H. L. Swanson, K. R. Harris, \& S. Graham (Eds.), Handbook of reading disabilities (2nd Ed., pp. 361-374). New York: Guilford Press.

Williams, J. P., Pollini, S., Nubla-Kung, A. M., Snyder, A. E., Garcia, A., Ordynans, J. G., et al. (2014). An intervention to improve comprehension of cause/effect through expository text structure instruction. Journal of Educational Psychology, 106, 1-17. https://doi.org/10.1037/a0033215.

Williams, J. P., Stafford, K. B., Lauer, K. D., Hall, K. M., \& Pollini, S. (2009). embedding reading comprehension training in content-area instruction. Journal of Educational Psychology, 101, 1-20. https ://doi.org/10.1037/a0013152. 